\title{
A survey of antimicrobial residues in table eggs in Khartoum State, Sudan, 2007-2008
}

\author{
Authors: \\ Mohamed M. Sirdar ${ }^{1,2}$ \\ Jackie Picard ${ }^{3,4}$ \\ Shahn Bisschop ${ }^{2}$ \\ Alexander R. Jambalang ${ }^{2}$ \\ Bruce Gummow ${ }^{2,4}$ \\ Affiliations: \\ ${ }^{1}$ Sayer Poultry Project, \\ Poultry Section, National \\ Cooperative Corporation, \\ Sudan \\ ${ }^{2}$ Department of Production \\ Animal Studies, University of \\ Pretoria, South Africa \\ ${ }^{3}$ Department of Tropical \\ Diseases, University of \\ Pretoria, South Africa \\ ${ }^{4}$ School of Veterinary and \\ Biomedical Sciences, James \\ Cook University, Australia \\ Correspondence to: \\ Mohamed Sirdar \\ Email: \\ sirdar44@hotmail.com \\ Postal address \\ Private Bag X04, \\ Onderstepoort 0110, \\ South Africa \\ Dates: \\ Received: 14 July 2011 \\ Accepted: 03 Nov. 2011 \\ Published: 16 Apr. 2012 \\ How to cite this article: \\ Sirdar, M.M., Picard, J. \\ Bisschop, S., Jambalang, \\ A.R. \& Gummow, B., 2012, \\ 'A survey of antimicrobial \\ residues in table eggs in \\ Khartoum State, Sudan, \\ 2007-2008', Onderstepoort \\ Journal of Veterinary \\ Research 79(1), Art. \#360, \\ 9 pages. http://dx.doi. \\ org/10.4102/ojvr.v79i1.360
}

(C) 2012. The Authors. Licensee: AOSIS OpenJournals. This work is licensed under the Creative Commons Attribution License.
The risk to consumers of antimicrobial residues in table eggs produced in Khartoum State, Sudan, was studied. All producing layer farms $(n=175)$ in the state were sampled in April, June and August 2008. A total of 933 eggs from 335 layer houses were screened for antimicrobial residues by using the growth inhibition of Geobacillus stearothermophilus var. calidolactis in-house test. A high proportion of layer farms (72\% in April, 61\% in June and 66\% in August) and layer houses (63\% April, 59\% in June and 61\% in August) were found to have antimicrobial residues, with no significant difference in prevalence $(p=0.57)$ between study periods. The study showed that the consumer was at constant risk of exposure to antimicrobial residues in table eggs. The paper discusses reasons for the high prevalence of antimicrobial residues in Sudanese eggs and its implications, and makes recommendations to address this important public health problem.

\section{Introduction}

The Sudanese poultry industry is located principally in Khartoum State which is the source for $90 \%$ of the country's production. The total poultry population in Sudan is estimated at 45 million. The commercial sector comprises 30 million chickens of which 20 million are layer hens. It contributes $45 \%$ of the agricultural income of the State, whilst the latter (agricultural income) contributes $7 \%$ of the total income (Ministry of Agriculture, Animal Resource and Irrigation 2005).

Antimicrobials are used by the poultry industry to enhance growth and feed efficiency and to reduce bacterial disease (Donoghue 2003). In layer hens, antimicrobials are used only to treat and to prevent bacterial infections. Antimicrobial classes used to treat poultry are similar to those used in human medicine and include aminoglycosides, tetracyclines, beta-lactams, quinolones, macrolides, polypeptides, amphenicols and sulphonamides (Stolker \& Brinkman 2005).

Antimicrobial residues may have a direct toxic effect on consumers, for example allergic reactions in hypersensitive individuals (Dayan 1993; Ormerod, Reid \& Main 1987; Woodward 1991). It has become necessary, therefore, that regulations are in place to ensure that antimicrobial residues are not present in animal products for human consumption at levels that may affect human health detrimentally.

Internationally recognised organisations such as the World Health Organisation (WHO), Food and Agriculture Organisation (FAO), Veterinary Medicine Directorate (VMD) of the European Union (EU), as well as the Food and Drug Administration in the USA (FDA), have set maximum tolerance levels or acceptable daily intakes (ADIs) for humans, and withholding times for pharmacologically active substances, including antimicrobial agents, prior to marketing (AlGhamdi et al. 2000). Surveillance systems should be in place in conjunction with these regulations to ensure that these standards are met and that analyses can detect antimicrobials at less than the maximum residue levels.

Sudan currently has neither regulations to govern the use of antimicrobials or the maximum allowable antimicrobial concentrations in food, nor does Sudan have any systems to monitor the presence of antimicrobial residues in animal products. The objective of this study was, therefore, to investigate the risk to consumers of antimicrobial residues in commercial layer eggs in Khartoum State, Sudan, given the lack of regulations.

\section{Materials and methods}

\section{Study design}

The study was conducted in Khartoum State where $90 \%$ of the country's eggs are produced. Khartoum State is divided into three localities, namely Khartoum, Khartoum North (Bahry) and 
Omdurman, which made up the sampling frame for the study (Figure 1). Most of these farms were situated close to the Nile River and consisted predominantly of smallholdings that made use of traditional open-houses. Egg samples were collected in all of these localities in April (mid-summer), June (the start of the rainy season) and August (the rainy season) 2008 to determine whether the season has any influence on the presence of antimicrobial residues in eggs. Three eggs were collected from each house: one close to the entrance, one in the center and one at the far end of each house, regardless of the number of houses on the farm. If one or more eggs from that house had antimicrobial residues, the house was considered as positive, thus increasing the sensitivity of the survey. If one or more houses were found to contain antimicrobial residues, the farm was considered as positive. It was assumed that mass in-water or mass in-feed treatment of houses was the method of choice when treating layers and therefore that antimicrobial residues should be equally present in all the eggs in the house at a specific time.

Each of the periods of egg collection was analysed as an independent survey because not all the farms were available for sampling for the different sampling periods. The reasons for this will be discussed later.

\section{Laboratory analysis}

Each egg sample was labeled with a unique number that corresponded to a data set that contained the date of collection, farm origin and the house number. The eggs were transported in carton storage trays at room temperature and were processed within 72 hours of collection. In a clean, dustfree room, the eggs were sprayed with $70 \%$ ethanol, allowed to air-dry and the tip of the shell at the air-sac was removed with scissors by using an aseptic technique. The contents were then poured into WhirlPak ${ }^{\circledR}$ plastic bags (Nasco, USA)

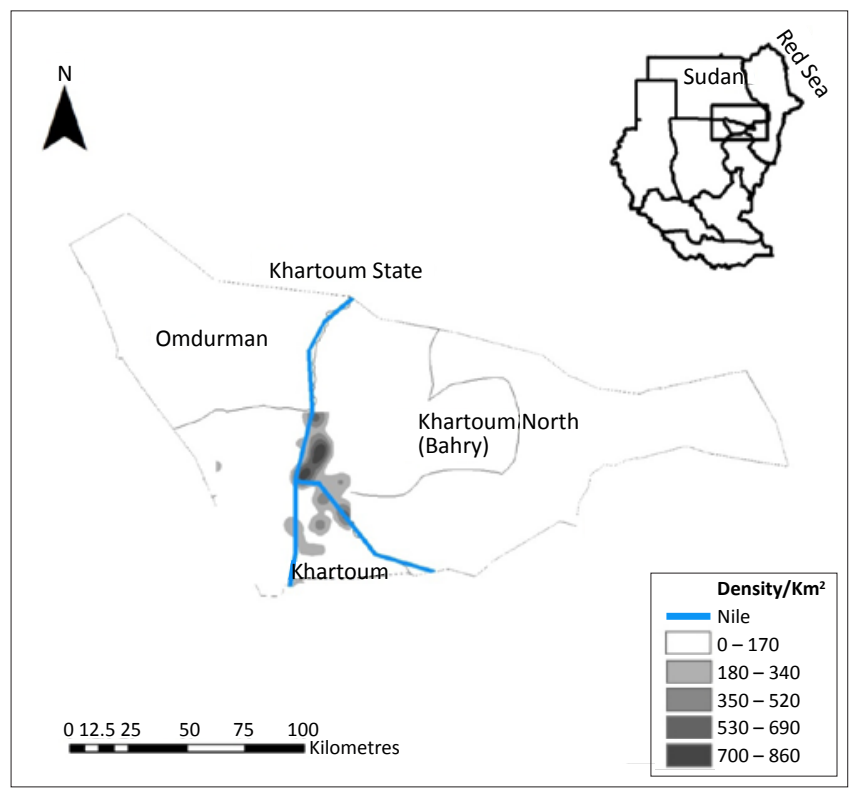

Source: Figure created from census data by using ArcGIS

FIGURE 1: Khartoum State map showing the three localities of the study area and the layer farm density in the State for $2007 / 2008$. labeled with the unique identifier number, farm origin, poultry house number and the date of collection and stored in a freezer $\left(-18^{\circ} \mathrm{C}\right)$ until processed.

After defrosting, each sample was homogenised with a Stomacher lab-blender 400 (Seward Medical, United Kingdom) and $100 \mu \mathrm{L}$ was added to $900 \mu \mathrm{L}$ of nutrient broth (Labretoria, South Africa) containing 1\% glucose (Merck Chemicals, South Africa), 0.002\% phenol red (Merck Chemicals, South Africa) and approximately $10^{5}$ colony forming units / $\mathrm{mL}$ of viable Geobacillus stearothermophillus var. calidolactis ATTC 7953 (Merck Chemicals, South Africa). The test was carried out in triplicate to increase sensitivity and to detect operator error. A control containing egg contents from hens that were known to be untreated with antimicrobials was used to check the viability of the organism and to determine the end-point of incubation. Samples were incubated in a water bath (Labotec, South Africa) at $80{ }^{\circ} \mathrm{C}$ for 10 minutes to destroy lysozyme and other protein inhibitors, as well as to stimulate the germination of G. stearothermophilus spores. The samples were then incubated at $65{ }^{\circ} \mathrm{C}$ for $2-4$ hours, depending on when the growth control changed from red to yellow. A colour change from red to yellow indicated glucose fermentation, whereas retention of the red colour indicated an inhibition of growth and hence the presence of inhibitors.

\section{Data analysis}

Data were collated and analysed with the Microsoft Excel (Microsoft Corporation, USA, 2003) spreadsheet program, and the comparison of the proportion of layer houses with antimicrobial residues in the three periods of collection were analysed with the Survey ToolBox (Animal Health Service, Australia) statistical package.

The sampling unit for determining the prevalence of residues within Khartoum State was the poultry house. A farm was considered as positive if one or more houses on the farm were found to contain eggs with antimicrobial residues and a house was considered as positive if one or more eggs contained detectable antimicrobial residues. The apparent prevalence $(\hat{p})$ derived from the survey is the number of farms with detectable antibiotic residues divided by the total number of farms sampled. The apparent prevalence was calculated separately for each period of collection.

Based on published results of a similar test, the sensitivity (Se) of the diagnostic test was assumed to be $72.5 \%$ and the specificity (Sp) as 98\% (Gaudin et al. 2009).

The $95 \%$ confidence interval for the true prevalence $(P)$ was calculated according to Cameron and Baldock (1998) by using the variance estimate $[\operatorname{var}(\hat{p})]$ of the apparent prevalence $(\hat{p})$ as follows:

$\operatorname{var}(\hat{p})=\frac{\hat{p}(1-\hat{p})}{n(S e+S p)^{2}}$

[Eqn 1]

where $(\hat{p})$ is the apparent prevalence, Se denotes sensitivity, $S p$ represents specificity, and $n$ indicates the sample size. 
The confidence interval for the true prevalence $(P)$ is then:

$$
\left[\hat{p}-\left(Z_{2} a x \sqrt{\operatorname{var}(\hat{p})}\right), \hat{p}+\left(Z_{\frac{a x}{2}} \sqrt{\operatorname{var}(\hat{p})}\right)\right]
$$

\section{Spatial analysis}

The mapping program, Google Earth version 4.3, was used to identify the farms and areas of sampling and to record the coordinates of all the farms sampled in Khartoum State. The main challenge was to record the coordinates of each farm sampled because they were clustered in each area with a difference of only seconds, or even fractions of a second, between them. All coordinates were entered into the spreadsheet program, Excel (Microsoft Corporation, USA, 2003). The Excel file was converted for use in ArcView 9.3 (Esri Redlands 2009). Africa, Sudan and Khartoum State shape files were downloaded from www. maplibrary.org (Map Maker Trust 2009).

Maps of Khartoum State that show the sampling locations, farm density, farms sampled and the prevalence of antibiotic residues for each period of collection, were created by using ArcView 9.3, as stated above.

\section{Results}

Prior to sampling (January 2008), a census was carried out of all the poultry farms in Khartoum State with the aim of repeat sampling of the same farms. The census showed that there were 252 layer farms, containing 764 houses, in the State.

A proportion of the eggs sampled in April had noticeable bacterial contamination when they arrived at the laboratory in South Africa, and consequently could not be analysed. The poor state of these samples was caused by an unexpected delay when the samples were couriered from Sudan to South Africa and, in addition, the samples were delayed at the airport for irradiation before clearance. Originally 290 eggs were sampled in April 2008; however, the delays and preservation difficulties in the importation of the egg contents to South Africa meant that 111 eggs had to be discarded, which left a total of 43 farms and 68 houses from which eggs could be processed.

In total, 933 eggs were analysed from 335 layer houses on 175 farms of which 43 farms (68 houses) were sampled in April 2008, 79 farms (154 houses) in June 2008, and 53 farms (113 houses) in August of the same year. Of the 933 eggs, 197 (21\%) were collected in April 2008, 427 (46\%) in June, and 309 (33\%) in August 2009.

The areas sampled in the survey and the number of houses in each area surveyed, as well as the number of houses that were found to have eggs with antimicrobial residues, and the 95\% confidence intervals for the true prevalence of houses affected, for the three sampling periods, have been tabulated (Table 1).
The areas sampled in the survey in relation to the number of farms in each area surveyed, as well as the number of farms that were found to have houses with antimicrobial residues, and the $95 \%$ confidence intervals for the true prevalence of farms affected, for the three sampling periods, were tabulated as well (Table 2).

The spatial distribution of antimicrobial residues for each sampling period is shown (Figure 2, Figure 3 and Figure 4, respectively). Of the farms sampled in April 2008, $72 \%$ had antimicrobial residues in them, whilst $63 \%$ of the layer houses in total had antimicrobial residues (Table 1 and Table 2). The $95 \%$ confidence interval for the true prevalence of antimicrobials in April on farms was $64 \%-80 \%$, and for houses $57 \%-70 \%$.

Farms sampled in June 2008, showed that $61 \%$ of the farms had antimicrobial residues. The proportion of layer houses with antimicrobial residues from farms with antimicrobial residues was 59\% (Table 1 and Table 2). The 95\% confidence interval for the true prevalence of antimicrobials in June on farms was $54 \%-67 \%$, and for houses $55 \%-64 \%$. On those farms with antimicrobial residues, an average of $90 \%$ of layer houses contained eggs with antimicrobial residues.

In August 2008, 66\% of the farms had antimicrobial residues in their eggs, whilst antimicrobial residues were detected in $61 \%$ of the layer houses (Table 1 and Table 2). The 95\% confidence interval for the true prevalence of antimicrobials in August on farms was $59 \%-74 \%$, and for houses $56 \%-66 \%$. On those farms with antimicrobial residues, an average of $83 \%$ of layer houses contained eggs with antimicrobial residues.

No difference in prevalence between sampling periods could be shown in Khartoum State farms or layer houses $(p$-value farms $=0.57$ and $p$-value layer houses $=0.88)$.

A comparison of the proportion of layer farms with antimicrobial residues in each area, for each period of collection (April, June and August), showed that only 'El-selait', and 'El-tibna \& Zakiab', had significant differences between the three periods with a $p$-value of 0.02 and 0.08 , respectively (Figure 2, Figure 3 and Figure 4).

\section{Discussion}

Only 175 farms (335 layer houses) participated in the survey in all three periods of collection because small farms were constantly changing their production status from a layer to a broiler set-up, or rearing pullets up to point-of-lay during the survey, which meant that not all farms, as reflected in the census, could be included in each sampling period. Another reason for not being able to sample all farms was that some owners were reluctant to participate in the survey, because of perceived biosecurity risks or a leaking of production information to competitors. This resulted in the inclusion of new farms or the exclusion of some farms in subsequent samplings; therefore, it was decided to regard each sampling 
TABLE 1: Number of houses sampled in 2008 and found positive for antimicrobial residues in each area sampled with $95 \%$ confidence interval for the true prevalence of houses with residues for each period sampled given below.

\begin{tabular}{|c|c|c|c|c|c|c|c|}
\hline \multirow[t]{2}{*}{ Locality } & \multirow[t]{2}{*}{ Area } & \multicolumn{2}{|c|}{ April } & \multicolumn{2}{|c|}{ June } & \multicolumn{2}{|c|}{ August } \\
\hline & & Houses sampled & Houses positive & Houses sampled & Houses positive & Houses sampled & Houses positive \\
\hline Bahry & El-selait & 4 & 3 & 18 & 9 & 10 & 10 \\
\hline Bahry & El-ezba & 0 & - & 10 & 10 & 0 & - \\
\hline Bahry & Halfaya al Muluk & 0 & - & 5 & 4 & 9 & 8 \\
\hline Bahry & El-samrab & 0 & - & 0 & - & 5 & 0 \\
\hline Bahry & Kabbashi & 0 & - & 6 & 3 & 3 & 2 \\
\hline Bahry & Elfaki Hashim & 0 & - & 6 & 3 & 10 & 5 \\
\hline Bahry & As saqqay & 0 & - & 7 & 1 & 7 & 4 \\
\hline Bahry & El-tibna \& Zakiab & 4 & 3 & 8 & 2 & 3 & 0 \\
\hline Bahry & As Sababi & 0 & - & 4 & 2 & 4 & 1 \\
\hline Bahry & Shambat & 15 & 9 & 8 & 6 & 5 & 4 \\
\hline Bahry & El-mazalat & 2 & 0 & 0 & - & 2 & 1 \\
\hline Bahry & Kuku & 0 & - & 6 & 5 & 3 & 2 \\
\hline Bahry & El-haj Usif \& El-shigla & 0 & - & 2 & 2 & 5 & 4 \\
\hline Bahry & Eid Babiker & 3 & 1 & 1 & 0 & 7 & 3 \\
\hline Khartoum & Butri & 0 & - & 4 & 3 & 0 & - \\
\hline Khartoum & Sawba Gharb & 14 & 8 & 8 & 7 & 8 & 6 \\
\hline Khartoum & Jurayf Gharb & 19 & 14 & 7 & 4 & 4 & 4 \\
\hline Khartoum & El-shigailab & 0 & - & 1 & 1 & 5 & 2 \\
\hline Khartoum & Eid Hussien & 0 & - & 3 & 1 & 0 & - \\
\hline Khartoum & Tyba Alhasanab & 0 & - & 2 & 1 & 0 & - \\
\hline Khartoum & El-salama & 2 & 1 & 1 & 0 & 0 & - \\
\hline Khartoum & Kalakilah \& Dikhanat & 5 & 4 & 20 & 7 & 8 & 5 \\
\hline Khartoum & Kalakilah Sharg & 0 & - & 6 & 3 & 0 & - \\
\hline Omdouman & Abo Rof & 0 & - & 1 & 0 & 0 & - \\
\hline Omdurman & El-garafa & 0 & - & 0 & - & 0 & - \\
\hline Omdurman & El-sarha & 0 & - & 0 & - & 0 & - \\
\hline Omdurman & Nefasha & 0 & - & 0 & - & 0 & - \\
\hline Total & & 68 & 43 & 154 & 91 & 113 & 69 \\
\hline \multicolumn{2}{|c|}{ True prevalence $95 \% \mathrm{Cl}(\%)$} & \multicolumn{2}{|c|}{$57-70$} & \multicolumn{2}{|c|}{$55-64$} & \multicolumn{2}{|c|}{$56-66$} \\
\hline
\end{tabular}

$\mathrm{Cl}$, confidence interval.

TABLE 2: Number of farms sampled in 2008 and found positive for antimicrobial residues in each area sampled with $95 \%$ confidence interval for the true prevalence of farms with residues for each period sampled given below.

\begin{tabular}{|c|c|c|c|c|c|c|c|}
\hline \multirow[t]{2}{*}{ Locality } & \multirow[t]{2}{*}{ Area } & \multicolumn{2}{|c|}{ April } & \multicolumn{2}{|c|}{ June } & \multicolumn{2}{|c|}{ August } \\
\hline & & Farms sampled & Farms positive & Farms sampled & Farms positive & Farms sampled & Farms positive \\
\hline Bahry & El-selait & 3 & 2 & 7 & 5 & 3 & 3 \\
\hline Bahry & El-ezba & 0 & - & 5 & 4 & 0 & - \\
\hline Bahry & Halfaya al Muluk & 0 & - & 2 & 2 & 3 & 2 \\
\hline Bahry & El-samrab & 0 & - & 0 & - & 2 & 0 \\
\hline Bahry & Kabbashi & 0 & - & 3 & 1 & 1 & 1 \\
\hline Bahry & Elfaki Hashim & 0 & - & 2 & 1 & 4 & 4 \\
\hline Bahry & As saqqay & 0 & - & 4 & 1 & 3 & 2 \\
\hline Bahry & El-tibna \& Zakiab & 3 & 2 & 5 & 2 & 3 & 0 \\
\hline Bahry & As Sababi & 0 & - & 2 & 1 & 2 & 1 \\
\hline Bahry & Shambat & 8 & 7 & 4 & 2 & 3 & 2 \\
\hline Bahry & El-mazalat & 1 & 0 & - & - & 1 & 1 \\
\hline Bahry & Kuku & 0 & - & 3 & 3 & 1 & 1 \\
\hline Bahry & El-haj Usif \& El-shigla & 0 & - & 1 & 1 & 2 & 2 \\
\hline Bahry & Eid Babiker & 2 & 1 & 1 & 0 & 4 & 2 \\
\hline Khartoum & Butri & 0 & - & 2 & 2 & 0 & - \\
\hline Khartoum & Sawba Gharb & 11 & 7 & 5 & 5 & 5 & 4 \\
\hline Khartoum & Jurayf Gharb & 9 & 8 & 5 & 3 & 2 & 2 \\
\hline Khartoum & El-shigailab & 0 & - & 1 & 1 & 4 & 2 \\
\hline Khartoum & Eid Hussien & 0 & - & 3 & 1 & 0 & - \\
\hline Khartoum & Tyba Alhasanab & 0 & - & 1 & 1 & 0 & - \\
\hline Khartoum & El-salama & 2 & 1 & 1 & 0 & 0 & - \\
\hline Khartoum & Kalakilah \& Dikhanat & 4 & 3 & 13 & 6 & 4 & 2 \\
\hline Khartoum & Kalakilah Sharg & 0 & - & 3 & 2 & 0 & - \\
\hline Omdouman & Abo Rof & 0 & - & 1 & 0 & 0 & - \\
\hline Omdurman & El-garafa & 0 & - & 0 & - & 0 & - \\
\hline Omdurman & El-sarha & 0 & - & 0 & - & 0 & - \\
\hline Omdurman & Nefasha & 0 & - & 0 & - & 0 & - \\
\hline$\overline{\text { Total }}$ & & 43 & 31 & 79 & 48 & 53 & 35 \\
\hline \multicolumn{2}{|c|}{ True prevalence $95 \% \mathrm{Cl}(\%)$} & \multicolumn{2}{|c|}{$64-80$} & \multicolumn{2}{|c|}{$54-67$} & \multicolumn{2}{|c|}{$59-74$} \\
\hline
\end{tabular}

$\mathrm{Cl}$, confidence interval. 


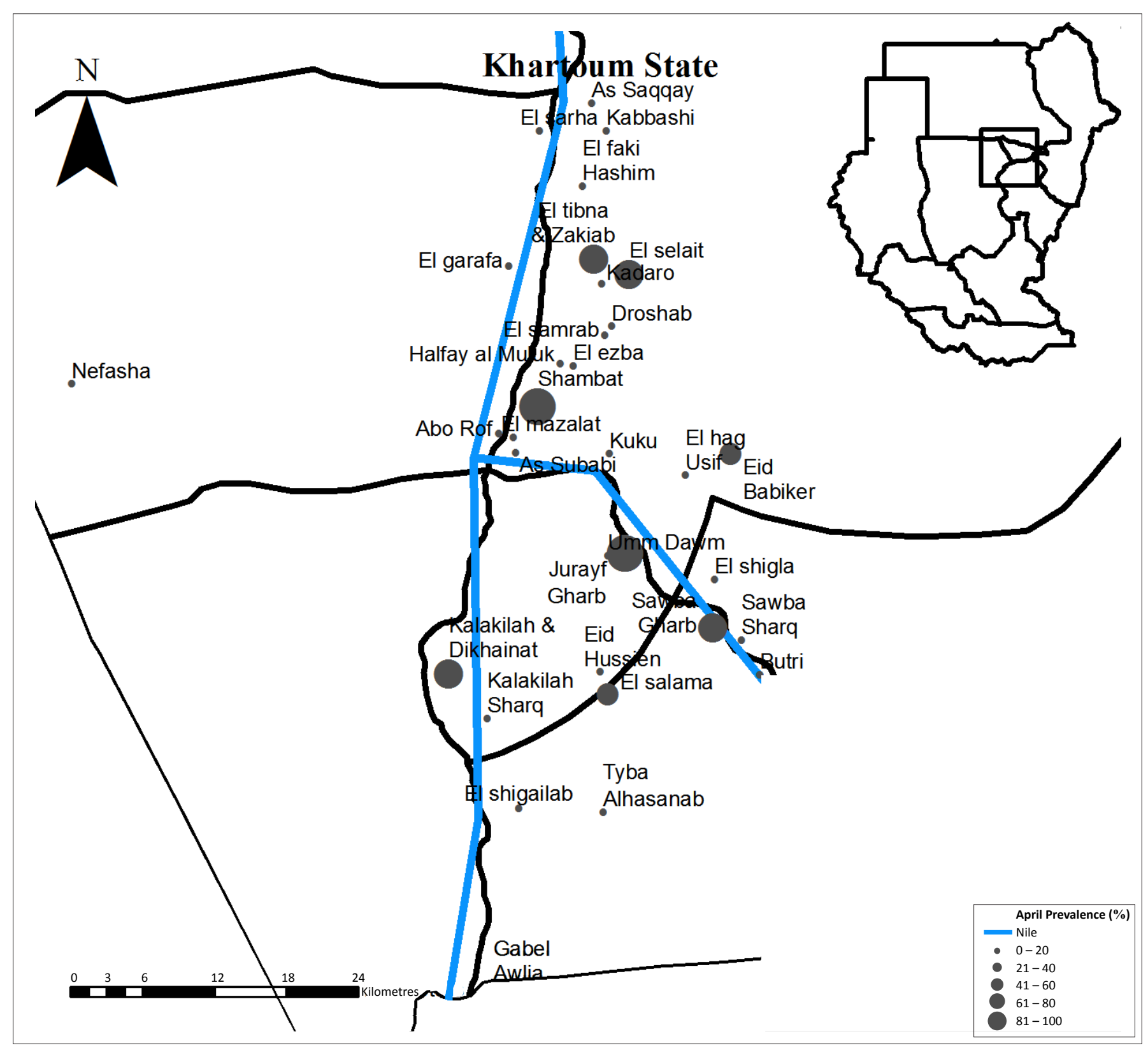

Source: Figure created from census data by using ArcGIS

FIGURE 2: Spatial distribution of antimicrobial residues in farms in Khartoum State surveyed in April 2008.

period as an independent survey. This may have resulted in some bias in the subsequent prevalence results but should not have impacted materially on the observed trends.

The June sampling had the highest number of sampled farms, followed by the August sampling. Fewer farms were available in August because of increased feed prices, which forced small producers to leave the business by either selling their flocks as spent hens or depopulating their flocks. In addition to that, August is the rainy season in Sudan, which results in damage to the inadequate poultry housing so that farmers do not keep laying flocks in this season. One reason for the result of the lowest number of productive farms in April is that most farmers start to rear pullets in winter (January and February), which means that their birds only come into lay in June.
There were some farms with only one house with antimicrobial residues, whilst the rest were negative. This is expected when antimicrobials are used therapeutically as only those houses with diseased birds will be supplied with medicated water. It was observed also that sometimes, within a layer house, one egg sample may be positive and the other two samples negative even though the study design assumed that all hens in a house were treated at the same time and thus that all eggs in a house would contain residues. The reason for this anomaly could be that eggs were collected shortly (within a day) after the withdrawal period of the drug treatment stopped, which resulted in very low concentrations in some eggs on the same farm. Another reason may be that, as most medications are either administered via the water or the feed, hens will vary in their uptake, absorption and secretion of antibiotic. On-farm factors that would have played a role as well are individual medications of birds, uneven 


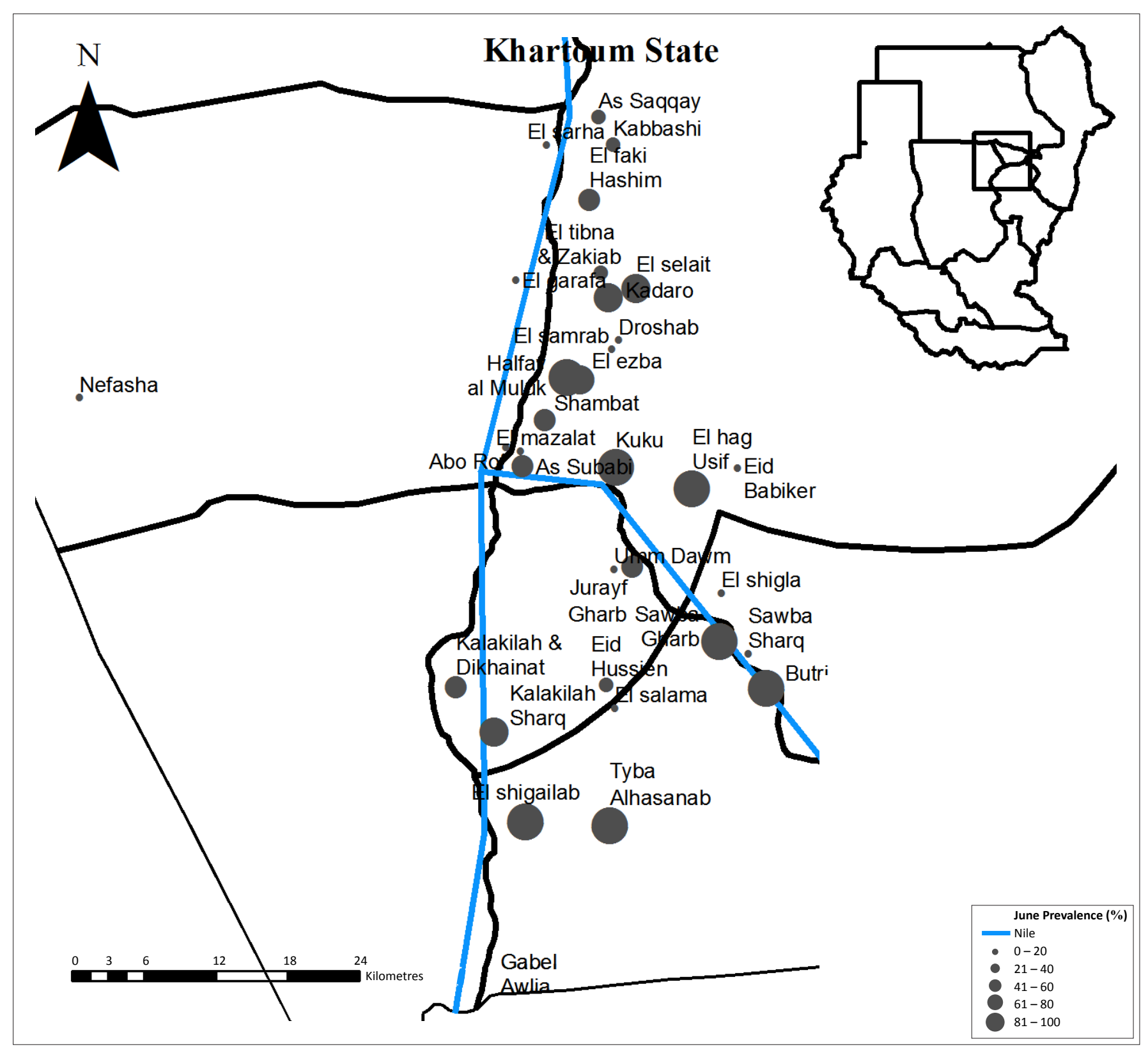

Source: Figure created from census data by using ArcGIS

FIGURE 3: Spatial distribution of antimicrobial residues in Khartoum State farms surveyed in June 2008.

distribution of the medicated feed and water, and the use of too low concentrations or aged antibiotics, which may have affected the sensitivity of the test. The screening test used also varies in its ability to detect antimicrobials. For example, it could detect the fluoroquinolones, penicillins, macrolides, tetracyclines, gentamicin and trimethoprim, at less than, or equal to, the Maximum Residue Limit (MRL), but varied in its ability to detect the sulphonamides and fosfomycin (Jambalang 2011).

A high prevalence of antimicrobial residues in April was detected in farms (Table 2) in Shambat (88\%), Jurayf Gharb (89\%), Kalakilah \& Dikhainat (75\%), El-tibna \& Zakiab (67\%), and El-selait $(67 \%)$. These areas are characterised by a high density of farms, which increases the risk of spread of diseases between farms, so that farms would use antimicrobials more readily. There are also more broiler farms amongst the layer farms in this region. El-mazalat had no antibiotic residues; however, only one open-house farm from a total of three farms was sampled in this area.

In spite of recording the lowest prevalence of antimicrobial residues in eggs in June, $41 \%$ of the areas screened had a prevalence of $80 \%$ or above. All the farms sampled in Kuku, Halfay al Muluk, El-haj Usif \& El-shigla, Butri, Sowba Gharb, Tyba Al-hasanab, and El-shigailab had antimicrobial residues in their eggs. This could be related to the fact that even though $22 \%$ of the all layer houses in the state were sampled in June 2008, only $9.4 \%$ of farms sampled were in areas of highest layer house densities (Halfay Al Muluk, As-saqqay and El-tibna \& Zakiab). Eid Babiker, El-salam and Abo Rof had no antimicrobial residue; however, the 


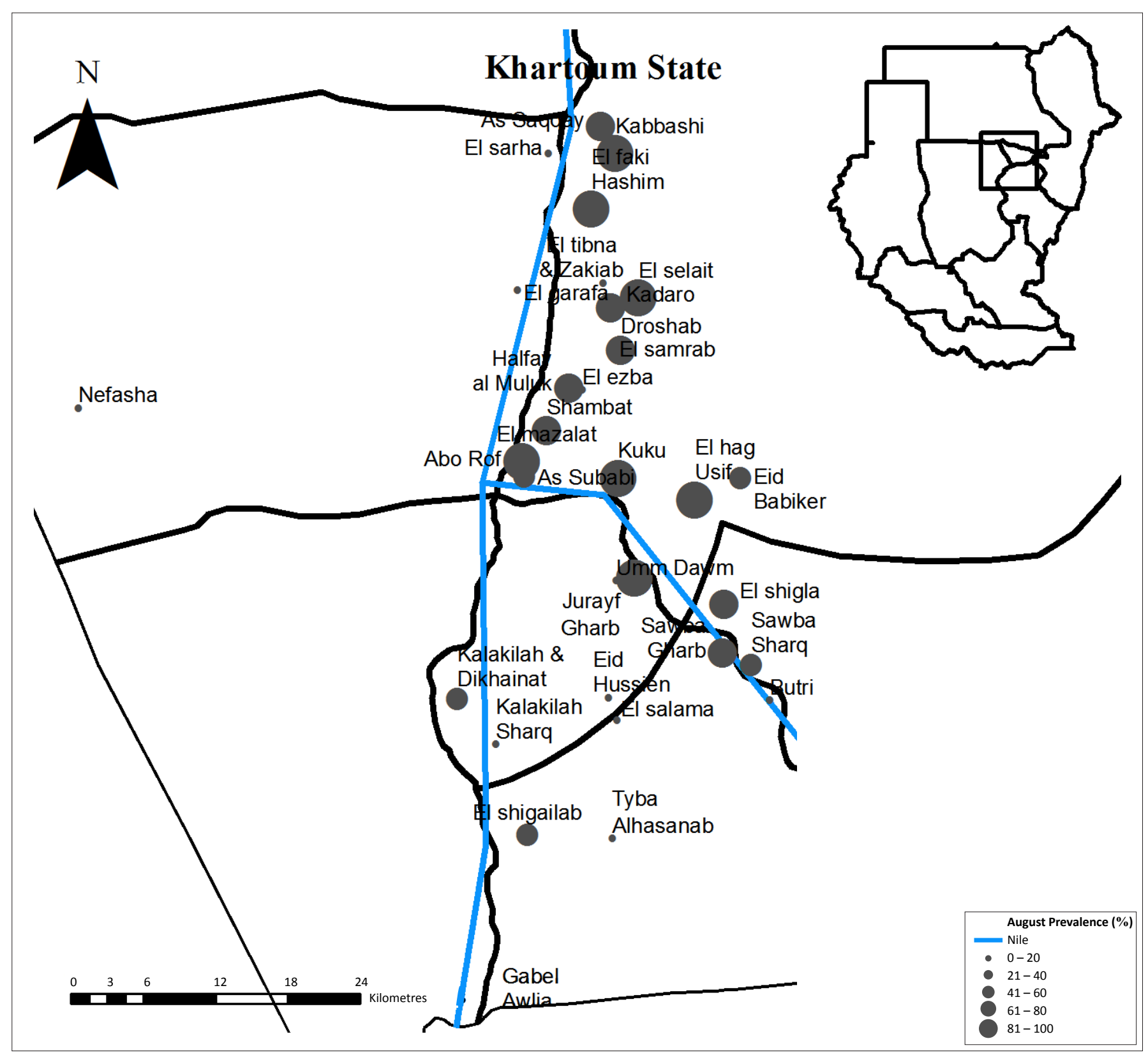

Source: Figure created from census data by using ArcGIS

FIGURE 4: Spatial distribution of antimicrobial residues in Khartoum State farms surveyed in August 2008.

sample size was not large enough to declare these areas free from antimicrobial residues because only one house was sampled per area. This makes it difficult to interpret the true prevalence of antimicrobial residues, which could change if all farms in these areas were productive.

Of the farms sampled in August, 66\% showed antimicrobial residues in the eggs, which were slightly higher than the June sampling and less than the April sampling. The same trend was observed when results were compared by poultry house, rather than by farm. A high prevalence (100\%) of antimicrobial residue was seen in El-haj Usif \& El-shigla, Elfaki Hashim, Kuku, El-selait, Sawba Gharb, El-mazalat, Kadaro \& Droshab Kabbashi and Jurayf Gharb. All the above mentioned areas were located along the Nile, and layer houses were affected by the moist environment. El-samrab was the only area that did not have antimicrobial residues.
There was no significant difference $(p=0.57)$ in the overall number of farms or layer houses $(p=0.88)$ with antimicrobial residues between the three periods of collection. This was surprising as it was expected that the antimicrobial use would be the highest during the rainy season (June-October) when infectious diseases in birds would be expected to peak as a result of insufficient housing to cope with the high rainfall and high humidity within these houses.

There was a significant difference, however, between individual sampled areas in the three collection periods. 'El-selait', and 'El-tibna \& Zakiab', showed a significant difference between all three periods of collection $(p=0.02)$ and ( $p=0.08)$, respectively. The difference was mainly because of the absence of antimicrobial residues in the samples collected from 'El-tibna \& Zakiab' in the August collection. The results for As-saqqay $(p=0.09)$, Kadaro \& Droshab $(p=0.05)$, and 
El-selait $(p=0.006)$, differed significantly between June and August. It is seen that only 1 out of 7 samples was positive in the samples collected from As-saqqay, and half of the 18 samples collected from El-selait showed antimicrobial residues in them in the June collection, whilst all samples collected in August in these areas were positive.

It is apparent, therefore, that most farmers use antimicrobials throughout the entire production cycle. Antimicrobials in layers are only administered therapeutically or to prevent disease, and consequently indicates that there is a high level of infectious disease on most farms. Infectious disease on smallholdings are common because of the close proximity of other farms, poor biosecurity, a hot climate and inadequate housing which allows pathogens to survive and can stress the birds. Furthermore, the lack of understanding of the effects of antimicrobial residues on human consumers and the lack regulations related to MRLs contributed to the high use of antimicrobials.

\section{Comparison of Khartoum State antimicrobial residue results with the results of other countries in Africa}

Published data on antimicrobial residues in eggs, or even in chicken meat, is scarce. This section highlights some results of surveys carried out in several countries, including results of surveys carried out on chicken meat, for comparative purposes.

Available data suggests that antimicrobial residues may be present in a large proportion of poultry products in developing countries, especially in Africa, the Middle East and South America. Similar to our results, Al-Ghamdi et al. (2000), who used the high-performance liquid chromatography (HPLC) method, reported an antimicrobial residue prevalence of $69.7 \%$ in chicken meat and $60 \%$ in eggs sampled from the eastern province of Saudi Arabia. A study conducted at Tehran, Iran, in 2006 by Salehzadeh et al. (2006), using HPLC, found that $95 \%$ of the 86 poultry farms tested had oxytetracycline residues in muscle, liver and kidney samples that were above the MRLs.

Nonga et al. (2009) carried out a study to assess antimicrobial residues in commercial chicken eggs in Morogoro Municipality in Tanzania. The study showed that all eggs sampled (70 eggs) and analysed with the Delvotest Kit, were positive for antimicrobial residues.

A study conducted in Senegal that made use of a variety of tests, including HPLC, revealed that $20 \%$ of the poultry farms sampled in 2001-2002 had antimicrobial residues in their meat products and $43 \%$ of the meat samples in $2003 \mathrm{had}$ antimicrobial residues in them (Bada Alambedji et al. 2008).

A study conducted in Nigeria (Kabir et al. 2004) found antimicrobial residues in $1 \%$ of the eggs sampled (200 eggs), and in $21.8 \%$ of 378 slaughtered broilers, using a disc diffusion microbial inhibition test with $B$. cereus and Micrococcus luteus. This test, however, is less sensitive to some classes of antibiotics than, for example, the Delvotest (Nonga et al. 2009).

A study conducted in Gauteng, South Africa, using the same microbial screening test as the study in Khartoum State, showed that $9.1 \%(6.4-12.5 \mathrm{CI})$ of the eggs tested were positive for antimicrobial residues (Jambalang 2011). By using a commercial scintigraphic test known as Charm II, Adesiyun et al. (2005) showed that the prevalence of antimicrobial residues in eggs in Trinidad was from eggs collected from farms (6.5\%), from markets $(16.1 \%)$ and from supermarkets $(15 \%)$. Both these countries have surveillance systems in place, but testing is selective.

In a study conducted in Kuwait to assess the prevalence of antimicrobial residues in eggs, tissue and feed samples also using the Charm II System, showed that all eggs sampled in a shopping center (222) were negative for antimicrobial residues. This study showed that the surveillance systems used in Kuwait for monitoring and applying the standards of antimicrobial residues in food is well-conducted and highly efficient (Alomirah et al. 2007).

The results of this study do not vary much from the results of other developing countries, even though the methods of analysis and sampling schemes are different. Many North African countries have a serious problem of antimicrobial residues in food available for human consumers. Much of this is a consequence of poor regulation and/or ignorance of the consequences of antimicrobials to human health.

\section{Conclusion}

In conclusion, the control of veterinary antibiotics used to ensure safer animal food products is needed in developing countries. Observation of drug withdrawal periods and extension programmes for farmers will be highly beneficial. Alternative practices such as vaccinations may reduce the use of antibiotics in poultry, the presence of antimicrobial residues and the development of drug resistant bacteria. This study serves as the first scientific evidence of the contamination of eggs by antimicrobial residues in Sudan. Although the concern of antimicrobial residues is an international issue and public health problem in eggs or food of animal origin in general, the study shows that there is a very high prevalence of antimicrobial residues in table eggs served for human consumption in Sudan. These findings revealed that all consumers in Sudan are probably at risk and urgent attention is needed. At present in Sudan, there are no routine programmes for monitoring antimicrobial residues in poultry products or in animal derived food. It is therefore recommended that The Ministry of Animal Resources and Fisheries and The National Standardization and Metrology Organization, who are responsible for the antimicrobial residues aspect in Sudan, need to construct comprehensive and well-designed regulations for antibiotic use in animals, set standards and limits for residues, monitor and survey products, and enforce compliance to ensure that only safe food is marketed and that consumers are protected. This study can serve as a baseline for the Sudanese authorities to monitor future intervention programmes. 


\section{Acknowledgements}

The authors thank the South African National Research Foundation (NRF) and the Malawian Islamic Zakaat Fund (IZF) for their financial assistance for this project. The work in this study was conducted as an approved research project (no. V047 / 07) of the University of Pretoria, South Africa, and met the ethical requirements for such research.

\section{Competing interests}

The authors declare that they have no financial or personal relationship(s) which may have inappropriately influenced them in writing this paper.

\section{Authors' contributions}

This work was conducted by M.M.S. (National Cooperative Corporation) as part of his MSc in epidemiology at the University of Pretoria. M.M.S. (National Cooperative Corporation) was involved in all aspects of the project and carried out the field work for the project and some of the laboratory analyses. The principle supervisor for this project was B.G. (University of Pretoria) who was responsible for the design and management of the project and the guidance of M.M.S. (National Cooperative Corporation) in all aspects of the project, but particularly for the epidemiology (data and spatial analysis). J.P. (University of Pretoria) acted as a cosupervisor and provided assistance and input principally into the microbiological components of the project (laboratory analysis). All three of these authors contributed extensively to the writing of this article. A.J. (University of Pretoria) assisted with some of the laboratory analyses and S.B. (University of Pretoria) acted as a co-supervisor to M.M.S. (National Cooperative Corporation), as well as a poultry consultant.

\section{References}

Adesiyun, A., Offiah, N., Lashley, V., Seepersadsingh, N., Rodrigo, S. \& Georges, K., 2005, 'Prevalence of antimicrobial residues in table eggs in Trinidad', Journal of Food Protection 68, 1501-1505. PMid:16013396

Al-Ghamdi, M., Al-Mustafa, Z., El-morsy, F., Al-Faky, A., Haider, I. \& Essa, H., 2000 'Residues of tetracycline compounds in poultry products in the eastern province 'Residues of tetracycline compounds in poultry products in the eastern province
of Saudi Arabia', Public Health 114, 300-304. http://dx.doi.org/10.1016/S0033of Saudi Arabia', Public Health 114,
3506(00)00350-4, PMid:10962596

Alomirah, H., Al-Mazeedi, H., Al-Zenki, S., Al-Faili, B., Al-Foudary, M., Abuzaid, A-H. et al., 2007, 'Prevalence of antimicrobial resides in eggs, tissues and feed samples in the State of Kuwait', Arab Gulf Journal of Scientific Research 25, 130-137.

Bada Alambedji, R., Akakpo, A.J., Teko Agbo, A., Chataigner, B., Stevens, A. \& Garin, B., 2008, 'Control of residues: example of antimicrobials in food in Senegal', Conference on Veterinary Medicinal Products in Africa, Dakar, 25-27 March.

Cameron, A.R. \& Baldock, F.C., 1998, 'A new probability formula for surveys to substantiate freedom from disease', Preventive Veterinary Medicine 34, 1-17. http://dx.doi.org/10.1016/S0167-5877(97)00081-0

Dayan, A.D., 1993, 'Allergy to antimicrobial residues in food: assessment of the risk to man', Veterinary Microbiology 35, 213-226. http://dx.doi.org/10.1016/03781135(93)90146-X

Donoghue, D.J., 2003, 'Antibiotic residues in poultry tissues and eggs: human health concerns?', Poultry Science 82, 618-621. PMid:12710482

Gaudin, V., Hedou, C., Rault, A., Sanders, P. \& Verdon, E., 2009, ‘Comparative study of three screening tests, two microbiological tube tests, and a multisulphonamide ELISA kit for the detection of antimicrobial and sulphonamide residues in eggs', Food Additives and Contaminants A 26, 427-440. http://dx.doi. org/10.1080/02652030802527626

Jambalang, A., 2011, 'The development and validation of a bacteriological screening test for antimicrobial residues in eggs', MSc Dissertation, Dept. of Tropical Diseases, University of Pretoria.

Kabir, J., Umoh, V.J., Audu-Okoh, E., Umoh, J.U. \& Kwaga, J.K.P., 2004, 'Veterinary drug use in poultry farms and determination of antimicrobial drug residues in commercial eggs and slaughtered chicken in Kaduna State, Nigeria', Food Control 15, 99-105. http://dx.doi.org/10.1016/S0956-7135(03)00020-3

Ministry of Agriculture, Animal Resource and Irrigation, Khartoum, Sudan, unpublished data, 2005.

Nonga, H.E., Simon, C., Karimuribo, E.D. \& Mdegela, R.H., 2009, 'Assessment of antimicrobial usage and residues in commercial chicken eggs from small holder poultry keepers in Morogoro Municipality, Tanzania', Zoonoses and Public health 57, 339-344. PMid:19486498

Ormerod, A.D., Reid, T.M. \& Main, R.A., 1987, 'Penicillin in milk: its importance in urticaria', Clinical Allergy 17, 229-234. http://dx.doi. org/10.1111/j.1365-2222.1987.tb02007.x

Salehzadeh, F., Madani, R., Salehzadeh, A., Rokni, N. \& Golchinefar, F., 2006 'Oxytetracycline residue in chicken tissues from Tehran slaughterhouses in 'Oxytetracycline residue in chicken tissues from Tehran slaughterhouses in
Iran', Pakistan Journal of Nutrition 5, 377-381. http://dx.doi.org/10.3923/ pjn.2006.377.381

Stolker, A.A. \& Brinkman, U.A., 2005, 'Analytical strategies for residue analysis of veterinary drugs and growth-promoting agents in food-producing animals - a review', Journal of Chromatography 1067, 15-53. http://dx.doi.org/10.1016/j. chroma.2005.02.037, PMid:15844509

Thrusfield, M., 2005, Veterinary Epidemiology, 3rd edn., Blackwell Science Ltd, Oxford, UK.

Woodward, K.N., 1991, 'Hypersensitivity in humans and exposure to veterinary drugs', Veterinary and human toxicology 33, 168-172. PMid:2035248 